\title{
Control of Microdomain Orientation in Block Copolymer Thin Films by Electric Field for Proton Exchange Membrane
}

\author{
Joonwon Bae \\ Department of Applied Chemistry, Dongduk Women's University, Seoul, South Korea \\ Email: joonwonbae@gmail.com
}

Received 20 February 2014; revised 20 March 2014; accepted 27 March 2014

Copyright (C 2014 by author and Scientific Research Publishing Inc.

This work is licensed under the Creative Commons Attribution International License (CC BY).

http://creativecommons.org/licenses/by/4.0/

(c) (i) Open Access

\begin{abstract}
Owing to the recent push toward efficient energy storage/conversion devices, fuel cells have become a strong candidate for energy conversion equipments. On the other hand, block copolymer polyelectrolytes are interesting materials for proton exchange membranes in fuel cells. Thus a considerable attention has been paid to the development of block copolymer polyelectrolyte membranes. In this study, the microdomains in block copolymer polyelectrolytes were controlled by external electric fields to develop high performance membranes with improved proton conductivity. The microdomain alignments in sulfonated polystyrene-b-hydrogenated poly butadiene- $b$-polystyrene block copolymer electrolyte were monitored by cross-sectional transmission electron microscopy analysis. The proton conductivities of the block copolymer electrolyte membranes were measured before and after exposure to electric field. In addition, the morphological features of the block copolymer electrolyte were observed with small angle x-ray scattering and atomic force microscopy.
\end{abstract}

\section{Keywords}

Proton Conducting Membrane, Block Copolymer Polyelectrolyte, Microdomain Alignment, Electric Field, Fuel Cell, Proton Conductivity

\section{Introduction}

Recently, energy storage/conversion devices are attracting a considerable amount of interest from all fields of science and technology. These equipments include batteries, capacitors, fuel cells, and solar cells. Among these novel devices, fuel cells are the most strong candidate for the energy conversion systems, which can convert 
chemical energy directly into electric energy [1].

In order to improve the overall performances and efficiencies of fuel cells, it is critical to incorporate high performance proton conducting membranes (PCMs), especially in two kinds of popular fuel cells such as proton exchange membrane fuel cell (PEMFC) and direct methanol fuel cell (DMFC) [2] [3]. To date, the PCM based on sulfonated fluorocarbon polymer, for example, Nafion ${ }^{\circledR}$ is the most widely used one [4]. Even if Nafion has high proton conductivity and good thermal stability, its methanol permeability is too high to use in practical applications [4]. Therefore, several attempts have been made in order to develop Nafion ${ }^{\circledR}$ membranes exhibiting reduced methanol permeability while maintaining proton conductivity [4]-[8].

On the other side, numerous studies have been conducted on developing new PCMs using block copolymers (BCPs) over the past decades [9]-[19]. Attention to the block copolymer polyelectrolytes (BCPEs) as a candidate for PCMs has been paid, because they exhibit unique morphologies such as sphere, cylinder, lamellar, and gyroid due to the self assembled-nanostructures. It has been found that the microdomain structure in BCPEs is strongly dependent on the solvent [20], annealing condition [21], shear force [22], and film thickness [23]. Also, it is very important to understand transport properties such as proton conductivity and methanol permeability through BCPE membranes when the size, shape, and ordering directions of microdomains in the membranes are different [19] [24].

Among various BCPEs, the most extensively studied material for PCMs is BCPEs based on the thermoplastic elastomers such as styrene- $b$-ethylene/butylene- $b$-styrene (SEBS), which is derived from the hydrogenation reaction of triblock copolymer, styrene- $b$-butadiene- $b$-styrene [25]-[39]. The synthesis [25], properties [27] [28] [31] [32], and morphologies [37]-[39] of the SEBS BCPEsare well documented. Kim's group has reported the transport properties and morphological characteristics of sulfonated SEBS extensively [10] [38] [39].

Even if the chemical and physical properties of sulfonated SEBS BCPEs have been extensively investigated, however, the effect of microdomain alignments in SEBS BCPEs on the proton conductivity of PCMs has been scarcely investigated yet [40]. In this study, the microdomain orientations in sulfonated SEBS BCPEs were controlled by external electric fields. The dependence of proton conductivity on microdomain alignments was examined by transmission electron microscopy (TEM) and conductivity measurements. It is certain that this work provides fundamental information for understanding the structure-property relation in BCPE PCMs.

\section{Experimental}

\subsection{Materials}

A block copolymer, styrene- $b$-ethylene/butylene- $b$-styrene (SEBS, $80 \mathrm{Kg} / \mathrm{mol}, 28 \mathrm{wt} . \%$ polystyrene) was supplied by Kuraray (SEPTON). The block copolymer was sulfonated to prepare sulfonated SEBS (sSEBS) according to the well-established procedure in the previous literature [25]. The sulfonating reagent was acetyl sulfate. The degree of sulfonation was found $22 \mathrm{~mol} \%$ /hard segment by elemental analysis. Figure 1 exhibits the chemical structure of sSEBS BCPE. A solvent, tetrahydrofuran (THF) was dried by a common method.

\subsection{Preparation of Thin sSEBS Films}

A solution of sSEBS in THF was prepared and filtered. Concentration of the solution was $3 \mathrm{wt} . \%$. A sSEBS film was spin-coated onto silicon wafer at $2000 \mathrm{rpm}$ for $60 \mathrm{~s}$ from the solution. Then the films were dried under ambient conditions until complete evaporation of solvent.

\subsection{Preparation of Thick sSEBS Films for SAXS}

A 10 wt.\% solution of sSEBS in THF was prepared and poured into a glass dish. Then the film was placed at



Figure 1. Chemical structure of the sulfonated SEBS electrolyte. 
room temperature until complete evaporation of solvent. The membrane was recovered as a flat-sheet type and the thickness was measured at dry state using a digital micrometer.

\subsection{Application of Electric Field}

Figure 2 shows the diagram of experimental apparatus for application of electric field to the prepared sSEBS film. An aluminized Kapton film served as the top electrode and asilicon wafer covered with Al foil as the other. A thin layer (20 - $25 \mu \mathrm{m})$ of cross-linked PDMS (Sylgard) was used as a buffer layer between the Kapton electrode and the copolymer thin film. The PDMS layer conforms to the electrode surface, eliminates air gaps between the top electrode and the copolymer film, and maintains asmooth surface of the copolymer film. The copolymer films were heated to $130^{\circ} \mathrm{C}$ under $\mathrm{N}_{2}$ with an applied electric fieldof $20 \mathrm{~V} / \mu \mathrm{m}$ for $6 \sim 12 \mathrm{~h}$ and then quenched to room temperature before removing the electric field.

\subsection{Proton Conductivity and Water Uptake Measurement}

The membranes were immersed in deionized water at least $6 \mathrm{~h}$ before measurements.Proton conductivity was measured using a complex impedance analyzer (ZAH-NER IM-6). AsSEBS membrane was sandwiched between two stainless electrodes and an ac perturbation of $1 \mathrm{~V}$ was applied to the cell.

The membranes were soaked for at least 3 days in deionized water and weighed to determine the uptake contents. Weight of a dried membrane was measured after drying the sample at $60^{\circ} \mathrm{C}$ under vacuum overnight. The uptake content was calculated by

$$
\text { Uptake content }(\%)=\frac{w_{\text {wet }}-w_{d r y}}{w_{d r y}} \times 100
$$

where $w_{d r y}$ and $w_{\text {wet }}$ are the mass of dried and wet samples, respectively.

\subsection{Instrumentations}

Small angle X-ray scattering (SAXS) patterns were obtained with a Bruker AXS Nanostar small angle X-ray scattering spectrometer with a generator voltage of $40 \mathrm{KV}$ and a current of $35 \mathrm{~mA}$. Scanning force microscopy (SFM) images were obtained in both the height and phase-contrast mode using a Digital Instruments Dimension 3100 scanning force microscope in a tapping mode. Transmission electron microscopy (TEM) experiments were performed with a JEOL 200CX TEM operated at an accelerating voltage of $200 \mathrm{kV}$. To prepare cross-sectional TEM specimens, a thin layer of carbon was evaporated onto the film surface before embedding in epoxy resin to prevent the diffusion of the epoxy resin into hybrid thin film. The thin film was then embedded in an epoxy resin and cured at $60^{\circ} \mathrm{C}$ for $12 \mathrm{~h}$. The films were removed from the substrate by dipping into liquid $\mathrm{N}_{2}$. Ultrathin sections $(60 \mathrm{~nm})$ were collected at room temperature using a Leica Ultracut Microtome, equipped with a diamond knife. The thin sections were exposed to $\mathrm{RuO}_{4}$ for 10 min to enhance the contrast.

\section{Results \& Discussion}

In determining sulfonation degree from the elemental analysis result, it must be assumed that the sulfonation takes place exclusively on the polystyrene end blocks. It should be mentioned that the sulfonation degree actually obtained is significantly lower than the expected value [25]. The efficiency of sulfonation employed in this study is approximately $22 \%$.



Figure 2. Schematic diagram of the experimental apparatus for application of electric field. 
In addition, it is well known that proton conducts through the ionic channels or the water clusters where water or methanol molecules are likely to swell a polymer matrix. The membranes prepared in this study have hydrophilic sulfonic acid groups enough to show the high proton conductivity because of their morphologies with percolated ionic channels [10]. In general, the proton conductivity is primarily dependent on the concentration of sulfonic acid groups. More specifically, the proton conductivity is closely related to the average number of water molecules per fixed sulfonic acid group [39]. Therefore, the water uptake content was measured for sSEBS membranes using Equation (1). The obtained water uptake for pristine sSEBS film was approximately 20 wt.\% regardless of film thickness. It was also revealed that the exposure to electric field did not significantly change the water uptake amount.

Figure 3 illustrates SAXS profiles of sSEBS film cast from THF before (solid line) and after (dotted line) thermal annealing at $130^{\circ} \mathrm{C}$ under $\mathrm{N}_{2}$ for $48 \mathrm{~h}$. THF was selected as solvent in this experiment because it is a good solvent for both constituent blocks. In addition, the molecular architecture of sSEBS in THF was clearly examined [28]. The thermal annealing has been performed well above the glass transition temperature $\left(T_{g}\right)$ of both blocks, 100 and $-40^{\circ} \mathrm{C}$ for PS and PEB, respectively. It is shown that the sSEBS membrane have lamellar microdomain morphology as indicated by the presence of maxima at positions with ratios of 1:1.95. The peak positions up to the second correlation peak are well resolved for the curve. It is known that the microscopically arranged lamellae of block copolymers exhibit the position of maximum intensity at $q$ values o 1, 2, 3, 4, etc. It was also found that the apparent spacing (D) by using Bragg's equation, $D=2 \pi / q_{\max }$, was estimated to be 35.1 $\mathrm{nm}$ from the position of first-order peak. It is accepted that the d-spacing is remarkably influenced by the solvent, water uptake, and sulfonation degree [38] [39].

Figure 4 displays the tapping mode phase image of the sSEBS sample. The unique morphology consisting of bright and dark microdomain is observed remarkably. For sSEBS (14/72/14), an intermediate between the cylinder and lamellar structure is formed. It has been reported that a further slight increase in PS weight ratio changed the microstructure to a well-ordered lamellar [37]. The obtained morphology appears worm-like with lamellar regions dispersed throughout, and might be termed "frustrated" due to the relative disorder [41].

Figure 5 exhibits the cross-sectional TEM images of sSEBS membrane obtained before and after exposure to electric field $(20 \mathrm{~V} / \mu \mathrm{m})$. Figure 5(a) shows the equilibrium microstructure of sSEBS after thermal annealing at $130^{\circ} \mathrm{C}$ under $\mathrm{N}_{2}$ for $48 \mathrm{~h}$. The microdomain morphology is apparently lamellar throughout the entire film, where the bright and dark regions correspond to elastomer and polystyrene, respectively. This phenomenon can be explained by the following reasoning.

As for block copolymer thin film, the mean field theory (including Flory-Huggins) offers a fundamental concept of phase separation. In particular, the lamellar phases of triblock copolymer are well-described by strong segregation theory [42]. It has been shown that the domain spacing $(D)$ for the lamellar structures of block copolymer is dependent on three physical parameters such as volume fraction of chain $(\phi)$, molecular weight $(N)$, and interaction parameters $(\chi)$ between blocks when the morphology shows lamellar phases. However, it is often

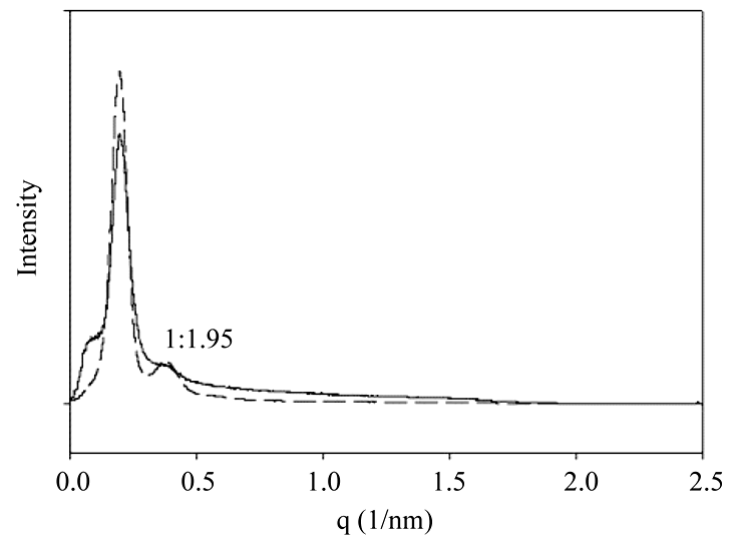

Figure 3. Small angle $x$-ray scattering patterns of the sulfonated SEBS membrane having an equilibrium microstructure obtained before (solid) and after (dotted) thermal annealing at $130^{\circ} \mathrm{C}$ under $\mathrm{N}_{2}$ for $48 \mathrm{~h}$. 


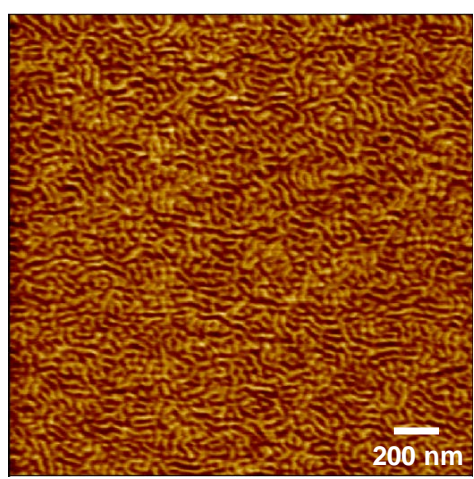

Figure 4. Scanning force microscopy phase image of the as-spun sulfonated SEBS membrane obtained at tapping mode.



Figure 5. Cross-sectional TEM images of the sulfonated SEBS membranes (a) thermally annealed at $130^{\circ} \mathrm{C}$ under $\mathrm{N}_{2}$ for $48 \mathrm{~h}$, exposed to electric field of 20 $\mathrm{V} / \mu \mathrm{m}$ for (b) $6 \mathrm{~h}$ and (c) $12 \mathrm{~h}$ at $130^{\circ} \mathrm{C}$ under $\mathrm{N}_{2}$. The white and yellow arrows indicate the film/substrate and the film/air interfaces, respectively.

difficult to evaluate the exact values of interaction parameters, because the three parameters are strong dependent on temperature and compositions. Instead of interaction parameters, the solubility parameters are of use to understand the interaction between polymers. In particular, the solubility parameter is a useful measure of interaction between blocks, when polymers are partially functionalized with a group as seen in the BCPE employed in this study. Alternatively, the interaction parameter is given by

$$
\chi_{\text {SPS-EB }}=\left(\delta_{S P S}-\delta_{E B}\right)^{2} / \rho_{0} k_{b} T
$$

where $\delta_{i}$ is the solubility parameter of block $i, \rho_{0}$ the number density of the mono-unit, and $k_{b}$ the Boltzmann constant [43]. The reference values for $\delta_{P S}, \delta_{S P S}$, and $\delta_{E B}$ are $9.1,16.6$, and $7.8 \mathrm{cal}^{1 / 2} / \mathrm{cm}^{2 / 3}$, respectively [44]. It was calculated that the value of $\chi N$ for the sSEBS sample is approximately 200 at room temperature. According to this value, the morphology of sSEBS is likely to form a lamellar structure, as confirmed by Figure 5(a). It is commonly accepted that the $\chi N$ values were influenced by the intermolecular ionic aggregation within the partially sulfonated polystyrene domains. Furthermore, strong ionic interactions like hydrogen bondings play role of physical crosslinking, which might induce an effect of increasing molecular weight.

Figure 5(b) and Figure 5(c) present the cross-sectional TEM images of sSEBS films exposed to an electric field of $20 \mathrm{~V} / \mu \mathrm{m}$ as a function of exposure time. It is conspicous that the microdomains oriented normal to the surface, adapted to the direction of applied electric field (yellow arrow). When an applied electric field exceeds a critical value to overcome interfacial interaction, the surface/interface becomes unstable. The electric field aligns interfaces separating two dielectric blocks parallel to the electric field vector. This leads to the formation of arrays of microdomains normal to the surface to minimize the moment of electrostatic forces exerted onto the interface between two blocks, driven by differences in the dielectric constants of the two bodies at the interface [45].

It is also discernible that the alignments started locally after $6 \mathrm{~h}$ exposure and then extended to the overall range in the middle of BCP thin film under an electric field. It is notable that the vertical alignment extends completely to the film/substrate interface (white arrow). This is a strikingly different phenomenon from that 
Table 1. Summary of the proton conductivities of the membranes.

\begin{tabular}{cc}
\hline Sample & Proton conductivity $(\mathrm{S} / \mathrm{cm})$ \\
\hline As spun $(<1 \mu \mathrm{m})$ & 0.018 \\
Thin film $(<1 \mu \mathrm{m})$ exposed to e-field & 0.021 \\
Thick film $(30 \mu \mathrm{m})$ exposed to e-field & 0.029 \\
\hline
\end{tabular}

seen in most block copolymer thin films. This is because the presence of ionic functional groups in polystyrene block can promote the response of PS microdomain to the direction of electric field even at the vicinity of film/substrate interface. In this case, the electrostatic force on sulfonated polystyrene domain exerted by the electric field might easily surpass the interfacial energy [46].

The proton conductivities of sSEBS samples are summarized in Table 1 . The proton conductivity is intimately dependent on the various parameters such as sulfonation degree, water uptake, and methanol permeability. In this experiment, the effect of those parameters is excluded, because the other experimental parameters are fixed. For thin sSEBS membranes $(<1 \mu \mathrm{m})$, the proton conductivity slightly increased after application of electric field. On the contrary, the conductivity increased significantly by exposure to electric field for thick membrane. This is attributed to the facilitated formation of percolated conducting channels inside membrane through microdomain alignments. Meanwhile, the increased water uptake amount in thicker membrane might be of help to elevate the proton conductivity. However, the mere application of electric field did not elevate the proton conductivity significantly. This is because conductivity requires connectivity of microdomainsacross macroscopic length scales and obtaining this in the aligned orientation appears difficult, especially for thin films.

\section{Conclusion}

The dependence of proton conductivities on microdomain alignments in sulfonated SEBS block copolymer electrolytes was revealed. It could be concluded that the proton conductivities of sulfonated SEBS membranes were elevated by the application of electric field to promote microdomain alignments. In addition, a schematic pathway to microdomain orientation in sulfonated SEBS under electric field was presented. A more detailed study regarding this topic is underway. This article can provide an interesting outcome for understanding the structure-property relation in proton exchange membranes.

\section{Acknowledgements}

This study was supported by Dongduk Women’s University Grant [2012-02204].

\section{References}

[1] Baldauf, M. and Preidel, W. (1999) Status of the Development of Direct Methanol Fuel Cell. Journal of Power Sources, 84, 161-166. http://dx.doi.org/10.1016/S0378-7753(99)00332-8

[2] Rikukawa, M. and Sanui, K. (2000) Proton-Conduction Polymer Electrolyte Membranes Based on Hydrocarbon Polymers. Progress in Polymer Science, 25, 1463-1502. http://dx.doi.org/10.1016/S0079-6700(00)00032-0

[3] Elabd, Y.A. and Hickner, M.A. (2011) Block Copolymers for Fuel Cells. Macromolecules, 44, 1-11. http://dx.doi.org/10.1021/ma101247c

[4] Heitner-Wirguin, C. (1996) Recent advances in Perfluorinated Ionomer Membranes: Structure, Properties and Applications. Journal of Membrane Science, 120, 1-33. http://dx.doi.org/10.1016/0376-7388(96)00155-X

[5] Costamagna, P. and Srinivasan, S. (2001) Quantum Jumps in the PEMFC Science and Technology from the 1960s to the Year 2000; Part I. Fundamental Scientific Aspects. Journal of Membrane Science, 102, 242-252.

[6] Vielstich, W. and Ives, D.J.G. (1970)Fuel cells; Modern processes for the Electrochemical Production of Energy. Wiley, London.

[7] Tricoli, V. (1998) Proton and Methanol Transport in Poly (Perfluorosulfonate) Membranes Containing $\mathrm{Cs}^{+}$and $\mathrm{H}^{+} \mathrm{Ca-}$ tions. Journal of the Electrochemical Society, 145, 3798-3801. http://dx.doi.org/10.1149/1.1838876

[8] Tricoli, V., Carretta, N. and Bartolozzi, M. (2000) A Comparative Investigation of Proton and Methanol Transport in Fluorinated Ionomeric Membranes. Journal of the Electrochemical Society, 147, 1286-1290.

http://dx.doi.org/10.1149/1.1393351 
[9] Hickner, M.A., Ghassemi, H., Kim, Y.S., Einsla, B.R. and McGrath, J.E. (2004) Alternative Polymer Systems for Proton Exchange Membranes (PEMs). Chemical Reviews, 104, 4587-4612. http://dx.doi.org/10.1021/cr020711a

[10] Kim, J., Kim, B. and Jung, B. (2002) Proton Conductivities and Methanol Permeabilities of Membranes Made from Partially Sulfonated Polystyrene-Block-Poly (Ethylene-Ran-Butylene)-Block-Polystyrene Copolymers. Journal of Membrane Science, 207, 129-137. http://dx.doi.org/10.1016/S0376-7388(02)00138-2

[11] Elabd, Y.A., Napadensky, E., Sloan, J.M., Crawford, D.M. and Walker, C.W. (2003) Triblock Copolymer Ionomer Membranes: Part I. Methanol and Proton Transport. Journal of Membrane Science, 217, 227-242. http://dx.doi.org/10.1016/S0376-7388(03)00127-3

[12] Shi, Z.Q. and Holdcroft, S. (2005) Synthesis and Proton Conductivity of Partially Sulfonated Poly ([Vinylidene Difluoride-co-Hexafluoropropylene]-b-Styrene) Block Copolymers. Macromolecules, 38, 4193-4201. http://dx.doi.org/10.1021/ma0477549

[13] Park, M.J., Downing, K.H., Jackson, A., Gomez, E.D., Minor, A.M., Cookson, D., Weber, A.Z. and Balsara, N.P. (2007) Increased Water Retention in Polymer Electrolyte Membranes at Elevated Temperatures Assisted by Capillary Condensation. Nano Letters, 7, 3547-3552. http://dx.doi.org/10.1021/nl0726171

[14] Xu, K., Li, K., Khanchaitit, P. and Wang, Q. (2007) Synthesis and Characterization of Self-Assembled SulfonatedPoly (Styrene- $b$-Vinylidene Fluoride- $b$-Styrene) Triblock Copolymers for Proton Conductive Membranes. Chemistry of Materials, 19, 5937-5945. http://dx.doi.org/10.1021/cm071626s

[15] Saito, T., Moore, H.D. and Hickner, M.A. (2010) Synthesis of Midblock-Sulfonated Triblock Copolymers. Macromolecules, 43, 599-601. http://dx.doi.org/10.1021/ma9023125

[16] Chen, L., Hallinan, Jr., D.T., Elabd, Y.A. and Hillmyer, M.A. (2009) Highly Selective Polymer Electrolyte Membranes from Reactive Block Polymers. Macromolecules, 42, 6075-6085. http://dx.doi.org/10.1021/ma901272s

[17] Lee, H.-S., Roy, A., Lane, O., Dunn, S. and McGrath, J.E. (2008) Hydrophilic-Hydrophobic Multiblock Copolymers Based on Poly (Arylene Ether Sulfone) via Low-Temperature Coupling Reactions for Proton Exchange Membrane Fuel Cells. Polymer, 49, 715-723. http://dx.doi.org/10.1016/j.polymer.2007.12.023

[18] Bae, B., Miyatake, K. and Watanabe, M. (2010) Sulfonated Poly (Arylene Ether Sulfone Ketone) Multiblock Copolymers with Highly Sulfonated Block. Synthesis and Properties. Macromolecules, 43, 2684-2691. http://dx.doi.org/10.1021/ma100291z

[19] Csernica, J., Baddour, R.F. and Cohen, R.E. (1987) Gas Permeability of a Polystyrene-Polybutadiene Block Copolymer with Oriented Lamellar Domains. Macromolecules, 20, 2468-2471. http://dx.doi.org/10.1021/ma00176a024

[20] Brinkmann, S., Stadler, R. and Thomas, E.L. (1998) New Structural Motif Inhexagonally Ordered Cylindrical Ternary (ABC) Block Copolymer Microdomains. Macromolecules, 31, 6566-6574. http://dx.doi.org/10.1021/ma980103q

[21] Hajduk, D.A., Gruner, S.M., Rangarajan, P., Register, R.A., Fetters, L.J., Honeker, C., Albalak, R.J. and Thomas, E.L. (1994) Observation of a Reversiblethermotropic Order-Order Transition in a Diblock Copolymer. Macromolecules, 27, 490-501. http://dx.doi.org/10.1021/ma00080a024

[22] Morrison, F.A. and Winter, H.H. (1989) The Effect of Unidirectionalshear on the Structure of Triblock Copolymers. I. Polystyrene-Polybutadiene-Polystyrene. Macromolecules, 22, 3533-3540. http://dx.doi.org/10.1021/ma00199a006

[23] Heck, B., Arends, P., Ganter, M., Kressler, J. and Stühn, B. (1997) SAXS and TEM Studies on Poly(strene)-blockpoly(ethene-co-but-1-ene)-block-poly(styrene) in Bulk and at Various Interfaces. Macromolecules, 30, 4559-4566. http://dx.doi.org/10.1021/ma9617072

[24] Csernica, J., Baddour, R.F. and Cohen, R.E. (1989) Gas Permeability of Apolystyrene/Polybutadiene Block Copolymer Possessing a Misoriented Lamellar Morphology. Macromolecules, 22, 1493-1496. http://dx.doi.org/10.1021/ma00193a085

[25] Weiss, R.A., Sen, A., Willis, C.L. and Pottick, A. (1991) Block Copolymer Ionomers: 1. Synthesis and Physical Properties of Sulfonated Poly(styrene-ethylene/butylene-styrene). Polymer, 32, 1867-1874.

[26] Jacobs, P.M. and Jones, F.R. (1989) Diffusion of Moisture into Two-Phase Polymers. Journal of Materials Science, 24, 2331-2336. http://dx.doi.org/10.1007/BF01174492

[27] Weiss, R.A., Sen, A., Pottick, A. and Willis, C.L. (1991) Block Copolymer Ionomers: 2.Viscoelastic and Mechanical Properties of Sulfonated Poly(styrene-ethylene/butylene-styrene). Polymer, 32, 2785-2792. http://dx.doi.org/10.1016/0032-3861(91)90109-V

[28] Wu, C., Woo, K. and Jiang, M. (1996) Light-Scattering Studies of Styrene-(ethylene-co-butylene)-Styrene Triblock Copolymer and Its Sulfonated Ionomers in Tetrahydrofuran. Macromolecules, 29, 5361-5367. http://dx.doi.org/10.1021/ma960247+

[29] Adams, J.L., Quiram, D.J., Graessley, W.W., Register, R.A. and Marchand, G.R. (1998) Interaction Strengths in Sty- 
rene-Diene Block Copolymers and Their Hydrogenated Derivatives. Macromolecules, 31, 201-204. http://dx.doi.org/10.1021/ma9710500

[30] Ovejero, G., Perez, P., Romero, M.D., Guzman, I. and Diez, E. (2007) Solubility and Flory Huggins Parameters of SBES, Poly(Styrene-b-butene/ethylene-b-styrene) Triblock Copolymer, Determined by Intrinsic Viscosity. European Polymer Journal, 43, 1444-1449. http://dx.doi.org/10.1016/j.eurpolymj.2007.01.007

[31] Blackwell, R.I. and Mauritz, K.A. (2004) Dynamic Mechanical Properties of Annealed Sulfonated Poly(styrene-b[ethylene/butylene]-b-styrene) Block Copolymers. Polymer, 45, 3457-3463. http://dx.doi.org/10.1016/j.polymer.2004.02.010

[32] Chen, H., Hassan, M.K., Peddini, S.K. and Mauritz, K.A. (2011) Macromolecular Dynamics of Sulfonated Poly(Styrene-b-ethylene-ran-butylene-b-styrene) Block Copolymers by Broadband Dielectric Spectroscopy. European Polymer Journal, 47, 1936-1948. http://dx.doi.org/10.1016/j.eurpolymj.2011.07.005

[33] Han, C.D., Chun, S.B., Hahn, S.F., Harper, S.Q., Savickas, P.J., Meunier, D.M., Li, L. and Yalcin, T. (1998) Phase Behavior of Polystyrene/Polybutadiene and Polystyrene/Hydrogenated Polybutadiene Mixtures: Effect of the Microstructure of Polybutadiene. Macromolecules, 31, 394-402. http://dx.doi.org/10.1021/ma971309e

[34] Wang, Y., Shen, J.S. and Long, C.F. (2001) The Effect of Casting Temperature on Morphology of Poly(Styrene-ethylene/butylene-styrene) Triblock Copolymer. Polymer, 42, 8443-8446. http://dx.doi.org/10.1016/S0032-3861(01)00325-1

[35] Wang, L., Hong, S., Hu, H., Zhao, J. and Han, C.C. (2007) The Surface Morphology Evolution of an Ultrathin Film of Poly[styrene- $b$-(ethylene-co-butylene)- $b$-styrene] during Its Dewetting Process. Langmuir, 23, 2304-2307. http://dx.doi.org/10.1021/la063314u

[36] Wang, L., Zhao, J. and Han, C.C. (2008) Phase Separation of Polystyrene-b-(Ethylene-co-butylene)-b-styrene (SEBS) Deposited on Polystyrene Thin Films. Polymer, 49, 2153-2159.

[37] Wang, D., Fujinami, S., Liu, H., Nakajima, K. and Nishi, T. (2010) Investigation of True Surface Morphology and Nanomechanical Properties of Poly(styrene-b-ethylene-co-butylene-b-styrene) Using Nanomechanical Mapping: Effects of Composition. Macromolecules, 43, 9049-9055. http://dx.doi.org/10.1021/ma100959v

[38] Kim, J., Kim, B., Jung, B., Kang, Y.S., Ha, H.Y., Oh, I.H. and Ihn, K.J. (2002) Effect of Casting Solvent on Morphology and PhysicalProperties of Partially Sulfonated Polystyrene-block-poly(ethylene-ran-butylene)-block-polystyrene Copolymers. Macromolecular Rapid Communications, 23, 753-756. http://dx.doi.org/10.1002/1521-3927(20020901)23:13<753::AID-MARC753>3.0.CO;2-G

[39] Kim, B., Kim, J. and Jung, B. (2005) Morphology and Transport Properties of Protons and Methanol through Partially Sulfonated Block Copolymers. Journal of Membrane Science, 250, 175-182. http://dx.doi.org/10.1016/j.memsci.2004.10.025

[40] Park, M.J. and Balsara, N.P. (2010) Anisotropic Proton Conduction in Aligned Block Copolymer Electrolyte Membranes at Equilibrium with Humid Air. Macromolecules, 43, 292-298. http://dx.doi.org/10.1021/ma901980b

[41] Mauritz, K.A., Blackwell, R.I. and Beyer, F.L. (2004) Viscoelastic Properties and Morphology of Sulfonated Poly(styrene-b-ethylene/butylene- $b$-styrene) Block Copolymers (sBCP), and sBCP/[silicate] Nanostructured Materials. Polymer, 45, 3001-3016. http://dx.doi.org/10.1016/j.polymer.2003.12.078

[42] Matsen, M.W. (2000) Equilibrium Behavior of Asymmetric ABA Triblock Copolymer Melts, Journal of Chemical Physics, 113, 5539. http://dx.doi.org/10.1063/1.1289889

[43] Shibayama, M., Hashimoto, T. and Kawai, H. (1983) Ordered Structure Inblock Polymer Solutions. 5. Equilibrium and Nonequilibrium Aspects of Microdomain Formation. Macromolecules, 16, 1434-1443. http://dx.doi.org/10.1021/ma00243a006

[44] Krevelen, V. (1990) Properties of Polymers. 3rd Editon, Elsevier, New York, 189.

[45] Xu, T., Hawker, C.J. and Russell, T.P. (2003) Interfacial Energy Effects on the Electric Field Alignment of Symmetric Diblock Copolymers. Macromolecules, 36, 6178-6182. http://dx.doi.org/10.1021/ma034511s

[46] Wang, J.Y., Chen, W., Roy, C., Sievert, J.D. and Russell, T.P. (2008) Influence of Ionic Complexes on Phase Behavior of Polystyrene- $b$-poly(methyl methacrylate) Copolymers. Macromolecules, 41, 963-969. http://dx.doi.org/10.1021/ma071908d 